\title{
The value of the Kurtzke Functional Systems Scales in predicting incomplete bladder emptying
}

\author{
K Kirchhof*,1 and CJ Fowler ${ }^{2}$ \\ ${ }^{1}$ Department of Neuroradiology, University of Heidelberg Medical School, Germany; ${ }^{2}$ Department of Uro-Neurology, \\ The National Hospital for Neurology and Neurosurgery, University College London Hospitals Trust, London, UK
}

\begin{abstract}
Study design: A field study was conducted in 40 patients with multiple sclerosis (MS) by comparing their residual urine volumes with the Kurtzke Functional Systems Scales for pyramidal (PFS) or bladder functions (BFS).

Objectives: To determine whether raised residual urine volumes necessitating intermittent self catheterisation can be predicted by the PFS or BFS.

Setting: Department of Uro-Neurology, The National Hospital for Neurology and Neurosurgery, University College London Hospitals Trust, London, UK.

Methods: In 40 patients with MS, post micturition residual volumes were measured with ultrasound prior to any treatment of bladder dysfunction. The patients' symptoms were assessed using PFS and BFS. Correlation between PFS, BFS and post micturition residual volumes were calculated as were sensitivity and specificity of PFS and BFS in predicting incomplete bladder emptying with residuals above $100 \mathrm{ml}$.

Results: None of the patients with a PFS or BFS of 0 or 1 had a residual of more than $100 \mathrm{ml}$. There was a linear progression of maximal residuals with PFS and BFS. Correlation between PFS (BFS) and the post micturition residual volumes was $0.37(0.71)$.

Conclusion: Unless a patient with MS has a PFS or BFS of greater than 1 they are unlikely to have incomplete bladder emptying with post micturition residual volumes above $100 \mathrm{ml}$. With PFS of BFS greater than 1 measurement of the post voiding residual volume is mandatory.
\end{abstract}

Spinal Cord (2000) 38, 409-413

Keywords: multiple sclerosis; residual urine volume; self catheterisation; urological management; Kurtzke Functional Systems Scales

\section{Introduction}

The prevalence of bladder dysfunction in patients with multiple sclerosis has been estimated to be approximately $75 \%$, most commonly occurring as a consequence of impaired neural pathways between the pontine micturition center and the sacral cord. ${ }^{1}$ A combination of detrusor hyperreflexia and incomplete emptying is the most common bladder problem, incomplete emptying occurring as a result of poor detrusor contractions and detrusor sphincter dyssynergia. ${ }^{2}$ Treatment of bladder dysfunction using intermittent self catheterisation is determined by the post micturition residual urine volume. ${ }^{3}$ As a general rule, intermittent catheterisation is recommended if the residual urine volume is in excess of $100 \mathrm{ml}$. When discussing possible methods of management of incontinence with a patient, it would be helpful if there was

*Correspondence: K Kirchhof, Department of Neuroradiology, University of Heidelberg Medical School, Im Neuenheimer Feld 400, 69120 Heidelberg, Germany some means by which the presence or absence of a raised residual urine volume could be predicted either from the pyramidal deficits of the lower limbs ${ }^{1}$ or from the history of bladder complaints.

In this study we therefore looked at the relation between the post micturition residual volume and the Kurtzke Functional Systems Scales for pyramidal and bladder functions.

\section{Methods}

During a period of 2 months all inpatients and outpatients presenting to the Department of UroNeurology at the National Hospital for Neurology and Neurosurgery with a confirmed diagnosis of MS were included in the study. The value for the post micturition residual volume was taken as the first measurement of residual before any treatment of bladder dysfunction had been instituted. Patients with permanent indwelling urethral catheters were excluded, as were patients with any other medical disorder that 
might have caused impairment of bladder or pyramidal function. There were 14 men and 26 women, aged between 20 and 58 years. The time since the onset of MS ranged from 0 to 28 years. Post micturition residual volume measurement was performed in all patients with an ALOKA SSD-500 FEATURES convex sector ultrasound scanner (ultrasound frequency: $3.5 \mathrm{MHz}$; angle of view: 60 degrees; radius of curvature: $60 \mathrm{~mm}$; max. display depth: $22 \mathrm{~cm}$ ). Scanning in two planes was carried out and the post micturition residual volume $(V)$ was determined by the formula:

$$
\begin{gathered}
V=0,7 \cdot w \cdot h \cdot d \mathrm{ml}^{3} ; \\
w=\text { with }[\mathrm{cm}], h=\text { height }[\mathrm{cm}], d=\operatorname{depth}[\mathrm{cm}] .
\end{gathered}
$$

(see Appendix)

The patient's disability was assessed using the Kurtzke Functional Systems Scales for pyramidal and bladder and bowel functions (Table 1). In most instances the score assigned was the result of a consensus opinion following discussion between the two authors. When scoring the pyramidal dysfunction, patients that could walk without assistance were regarded to have 'minimal disability'. 'Mild or moderate paresis' was scored if power was at least $4 / 5$ on the standard Medical Research Council (MRC) scale, 'marked or severe paresis' if power was below 4/5. A lower limb was classified as 'plegic' if power of all muscles was $0 / 5$ with the exception of toe muscles.

Scoring the bladder dysfunction, urgency was regarded as 'mild' if the patient had a reasonable warning of impending micturition but 'moderate' if they must hurry to a toilet. Hesitancy was described as 'mild' if micturition could be initiated within $1 \mathrm{~min}$

Table 1 Kurtzke Functional Systems Scales for pyramidal functions (PFS) and bladder and bowel functions (BFS)

\begin{tabular}{ll}
\hline Pyramidal functions & Bladder functions \\
\hline 0 normal & $\begin{array}{c}\text { normal } \\
\text { disability } \\
2 \text { minimal disability } \\
\text { urgency or retention } \\
\text { moderate hesitancy, } \\
\text { urgency, retention of } \\
\text { bladder or bowel or } \\
\text { rare urinary incontinence }\end{array}$ \\
$\begin{array}{c}\text { mild or moderate } \\
\text { paraparesis or } \\
\text { hemiparesis; severe } \\
\text { monoparesis } \\
\text { marked paraparesis or } \\
\text { hemiparesis; moderate } \\
\text { quadriparesis; or } \\
\text { monoplegia }\end{array}$ & $\begin{array}{c}\text { incontinence } \\
\text { paraplegia, hemiplegia or } \\
\text { marked quadriparesis }\end{array}$ \\
$\begin{array}{c}\text { quadriplegia } \\
\text { catheterisation }\end{array}$ & $\begin{array}{c}\text { loss of bladder functions } \\
\text { loss of bladder and }\end{array}$ \\
\hline
\end{tabular}

otherwise it was scored as 'moderate'. Retention was defined as inability to pass urine despite the urge and was not used to score bladder functions. Urinary incontinence occurring at most once a month was described as 'rare', otherwise as 'frequent'.

Bowel complaints were not included whilst evaluating a figure for the bladder dysfunction.

Correlation after Spearman between the post micturition residual volumes and both the pyramidal and the bladder functions scores were calculated. With fourfold tables, sensitivity of different pyramidal and bladder functions scores in predicting complete bladder emptying with residual urine volumes below $100 \mathrm{ml}$ was determined, as was their specificity for incomplete bladder emptying with residuals above $100 \mathrm{ml}$.

\section{Results}

Whereas the Kurtzke Pyramidal Functions Scale was easy to assess, deriving a figure for the Kurtzke Bladder Scale was unsatisfactory for patients with severe hesitancy or urgency but without incontinence. These patients were inevitably either underscored and categorised as 2 'moderate' or overscored as 3 'frequently incontinent'.

The frequency of scores with the Kurtzke Functional Systems Scales for pyramidal and for bladder and bowel functions are shown in Figures 1 and 2. In three patients with a pyramidal functions score of 0 , two had normal bladder functions and one had a bladder functions score of 1 . Of those seven patients with a pyramidal functions score of 1 , three reported normal bladder functions whereas the bladder dysfunction of the remainder was scored as 2 . Amongst the 12 patients presenting with a pyramidal functions score of 2 , five had normal bladder functions, four had a bladder functions score of 2 , and in three patients bladder dysfunction was scored as 1 or 5 . Ten out of 12 patients presenting with a pyramidal functions score of 3 had a bladder functions

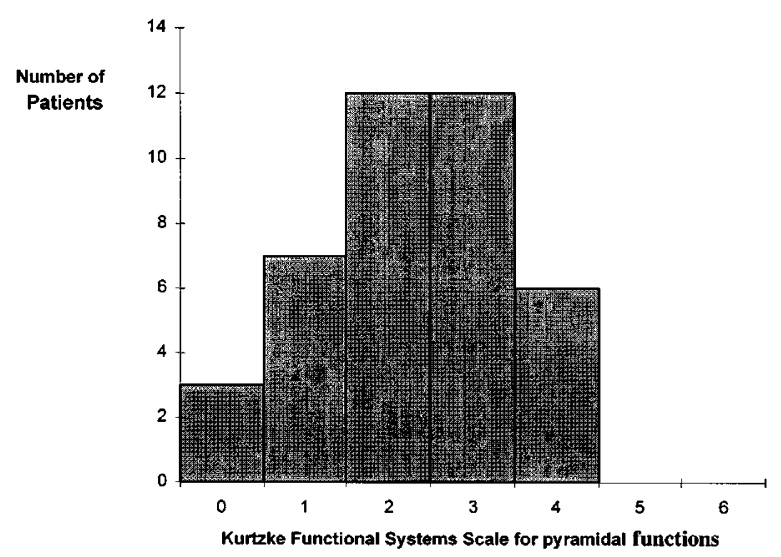

Figure 1 Frequency of Kurtzke Pyramidal Functions Scores in 40 patients with MS 
score of 2 , the remainder of 3 or 5 . In six patients whose pyramidal dysfunction was scored as 4 , bladder functions scores ranged from 1 to 4 in an equal distribution.

None of the patients with a pyramidal functions score of 0 or 1 had a residual of more than $100 \mathrm{ml}$ necessitating intermittent catheterisation (Figure 3). All three patients with a pyramidal functions score of 0 were able to empty their bladder completely. In those patients with a pyramidal functions score of 2 or higher, the residuals ranged from 0 to $525 \mathrm{ml}$. With the exception of the patient with a pyramidal functions score of 2 and a post micturition residual volume of $525 \mathrm{ml}$, there appears to be a linear progression of maximal residuals with the pyramidal functions scores.

It is apparent from Figure 4 that with any bladder complaints scored as 1 or less, the residual urine volume was below $100 \mathrm{ml}$. In patients with a bladder functions score of 2 , the residual urine volume varied

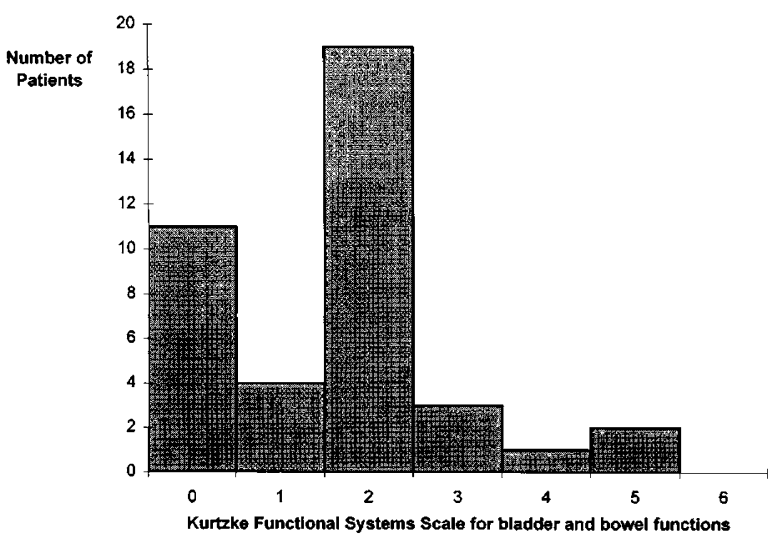

Figure 2 Frequency of Kurtzke Bladder Functions Scores in 40 patients with MS

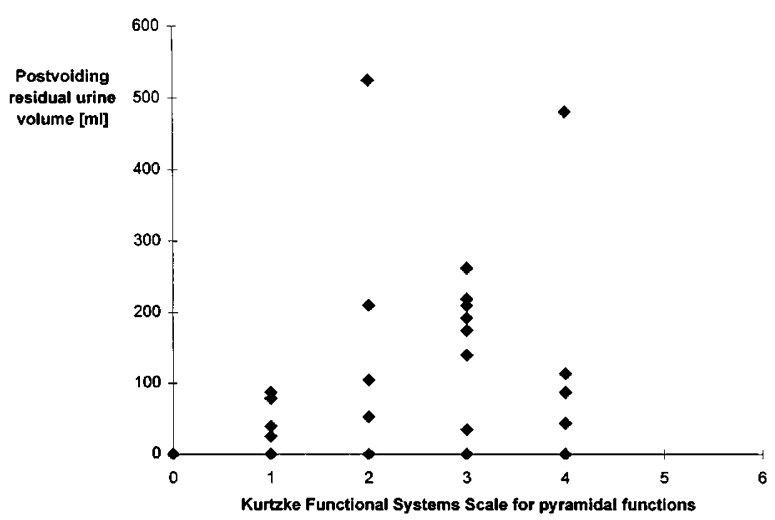

Figure 3 Postvoiding residual urine volume plotted against the Kurtzke Functional Systems Scale for pyramidal functions in 40 patients with MS. All patients with a bladder functions score of 0 or 1 had a residual below $100 \mathrm{ml}$ between 0 and $260 \mathrm{ml}$. Predictability of the residuals did not improve if bladder dysfunction was scored higher than 2. Again, there appears to be a linear progression of maximal residuals with the bladder functions scores.

Although all 10 patients with a pyramidal functions score of 1 or less had a post micturition residual volume below $100 \mathrm{ml}$, correlation after Spearman between the Kurtzke Pyramidal Functions Scale and the post micturition residual volumes was poor $(0.37)$. Despite the difficulties in scoring urinary dysfunction with the Kurtzke Functional Systems Scale, correlation between bladder functions scores and post micturition residual volumes was 0.71 .

Sensitivity of different pyramidal and bladder functions scores in predicting complete bladder emptying and their specificity in predicting incomplete bladder emptying are shown in Table 2.

\section{Discussion}

This study demonstrates that unless a patient with MS has a pyramidal or bladder functions score of greater than 1 , they are unlikely to have incomplete bladder

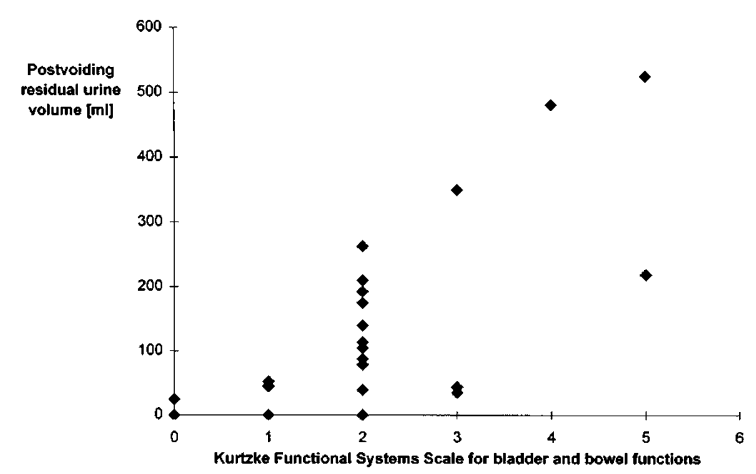

Figure 4 Postvoiding residual urine volume plotted against the Kurtzke Functional Systems Scale for bladder and bowel functions in 40 patients with MS. All patients with a bladder functions score of 0 or 1 had a residual below $100 \mathrm{ml}$

Table 2 Sensitivity of pyramidal and bladder functions scores in predicting complete bladder emptying with residual urine volumes below $100 \mathrm{ml}$ and their specificity in predicting incomplete bladder emptying with residual urine volumes above $100 \mathrm{ml}$

\begin{tabular}{llcc}
\hline & & Sensitivity & Specificity \\
\hline Pyramidal & $\mathrm{PFS} \leqslant 1$ & 0.36 & 1 \\
Functions & $\mathrm{PFS} \geqslant 2$ & 0.64 & 0 \\
Scores & $\mathrm{PFS} \geqslant 3$ & 0.32 & 0.25 \\
& & & \\
Bladder & $\mathrm{BFS} \leqslant 1$ & 0.54 & 1 \\
Functions & $\mathrm{BFS} \geqslant 2$ & 0.46 & 0 \\
Scores & $\mathrm{BFS} \geqslant 3$ & 0.07 & 0.67 \\
\hline
\end{tabular}


emptying with post micturition residual volumes above $100 \mathrm{ml}$. Fowler et $a l^{3}$ and Betts et $a l^{4}$ advocate residual bladder volume measurement before deciding which treatment is appropriate. It appears that this is not necessary if either pyramidal or bladder and bowel dysfunction is scored 1 or less using the Kurtzke Scales. Though there is a linear rise in maximal residuals with the pyramidal and the bladder and bowel functions scores, the variation in residuals means that there will be uncertainty as to whether clean intermittent self catheterisation is necessary. Depending on the functions scale used, sensitivity in predicting complete bladder emptying was $0.46-0.64$ in scores above 1 and $0.07-0.32$ in scores above 2 . This clearly indicates that residual volume measurement is essential if pyramidal or bladder dysfunction is scored 2 or higher because $36 \%$ of these patients had incomplete bladder emptying.

This study shows that disturbance of bladder functions is likely to occur in MS patients with lower limb pyramidal dysfunction ${ }^{1}$ : $90 \%$ of the patients presenting with pyramidal symptoms in the lower limbs also complained about bladder problems. Because nerve supply of the bladder has a more distal spinal representation than that of the lower limbs, one would also expect the severity of urinary symptoms to be related to the degree of pyramidal symptoms in the lower limbs. This was confirmed by Betts et $a .^{4}{ }^{4}$ Awad et $a l^{5}$ described a relationship between pyramidal dysfunction and detrusor areflexia or hyperreflexia. Contrary to this, Philp et $a l^{6}$ did not find correlation between neurologic findings and bladder symptoms. This is consistent with our results, showing a correlation between pyramidal functions scores and bladder functions scores of 0.54 . These contradictory findings might be explained by Honig et $a l^{7}$ pointing out that the Kurtzke Scales reflects spinal rather than cerebral demyelinisation. According to this, PFS should reach significant correlation with detrusor external sphincter dyssynergia (DESD) and impairment of voiding coordination (being due to spinal cord lesions), but not with impairment of voluntary initiation of micturition (being due to cerebral or brainstem lesions). Depending on the combination of these bladder problems, pyramidal and bladder functions scores would correlate more or less. To examine this hypothesis, we analysed data of patients with bladder functions scores below 4 and without hesitancy, assuming that their symptoms were mainly due to spinal cord lesions. Correlation between pyramidal and bladder functions scores did not improve significantly.

In practical terms the results of this study show that when a patient with MS presents with bladder symptoms but only mild locomotor disability, it is not necessary to explain the procedure of intermittent self catheterisation but that in patients with more significant disability, measurement of the post voiding residual volume is mandatory.

\section{References}

1 Fowler CJ, Kerrebroeck PEV, Nordenbo A, Poppel HV. Treatment of lower urinary tract dysfunction in patients with multiple sclerosis. Committee of the European Study Group of SUDIMS (Sexual and Urological Disorders in Multiple Sclerosis). J Neurol Neurosur Psychiatry 1992; 55: 986-989.

2 Mayo ME, Chetner MP. Lower urinary tract dysfunction in multiple sclerosis. Urology 1992; 39: 67-70.

3 Fowler CJ. Investigation of the neurogenic bladder. $J$ Neurol Neurosurg Psychiatry 1996; 60: 6-13.

4 Betts CD, D'Mellow MT, Fowler CJ. Urinary symptoms and the neurological features of bladder dysfunction in multiple sclerosis. J Neurol Neurosurg Psychiatry 1993; 56: 245-250.

5 Awad SA, Downie JW, Sogbein SK. Relationship between neurologic and urologic status in patients with multiple sclerosis. J Urol 1984; 132: 499.

6 Philp T, Read DJ, Higson RH. The urodynamic characteristics of multiple sclerosis. Br J Urol 1981; 53: 672-675.

7 Honig LS, Ramsay RE, Sheremata WA. Event-related potential P300 in multiple sclerosis. Relation to magnetic resonance imaging and cognitive impairment. Arch Neurol 1992; 49: 44-50.

8 Goodkin DE et al. Inter- and intrarater scoring agreement using grades 1.0 to 3.5 of the Kurtzke Expanded Disability Scale (EDSS). Multiple Sclerosis Collaborative Research Group. Neurology 1992; 42: 859-863.

9 Paltieli Y et al. Ultrasound assessment of the bladder volume after anterior colporrhaphy. Gynecol Obstet Invest 1989; 28: $209-211$.

10 Bis KG, Solvis TL. Accuracy of ultrasonic bladder volume measurement in children. Pediatr Radiol 1990; 20: 457-460.

11 Knorr H, Strauss I, Seichert N. Sonographische Zystometrie unter Berücksichtigung der Harnblasenform und der Harnblasenfüllung. Ultraschall Med 1990; 11: $150-154$.

12 Akino $\mathrm{H}$ et al. Ultrasound assessment of the intravesical urine volume. Hinyokika Kiyo 1990; 36: 655-660.

13 Roehrborn CG, Peters PC. Can transabdominal ultrasound estimation of post-voiding residual (PVR) replace catheterization? Urology 1988; 31: 445-449.

14 Haylen BT, Parys BT, West CR. Transrectal ultrasound to measure bladder volumes in men. $J$ Urol 1990; 143: 687-689.

15 Haylen BT, Franzer MI, Sutherst JR, West CR. Transvaginal ultrasound in the assessment of bladder volumes in women. Preliminary report. Br J Urol 1989; 63: 149-151.

\section{Appendix}

Discussing different correlations involving Kurtzke Scores, intra- and interrater reliability have to be taken into account ${ }^{8}$ as well as inaccuracy of residual volume measurement and calculation. Ultrasound scanning is now well accepted as a means of estimating the residual urine volume. There are many different recommendations how to increase accuracy of ultrasonic bladder volume measurement. By using the formula $V=d \cdot h \cdot w \mathrm{ml}^{3} ; w=$ with $(\mathrm{cm}), h=$ height $(\mathrm{cm})$, $d=$ depth $(\mathrm{cm})$, Paltieli et $a l^{9}$ found a mean error of less than $20 \%$ in $73 \%$ of their cases, if the true bladder volume was greater than $100 \mathrm{~cm}^{3}$. With the formula $V=0.9 \cdot d \cdot h \cdot w \mathrm{ml}^{3}$, Bis et al ${ }^{10}$ reduced the mean error in patients with normal bladder contours - irrespective of the bladder volume - to $11.5 \%$. Knorr et $a l^{11}$ suggest to apply the factor 0.9 only in volumes greater than $150 \mathrm{ml}$ whereas in those less than $150 \mathrm{ml}$ a factor of 1.25 was more accurate but fail to mention their mean error. The ellipsoid formula 


$$
V=\frac{\pi}{6} \cdot d \cdot h \cdot w \mathrm{ml}^{3}
$$

had an accuracy of $90.5 \%$ in residual volumes ranging from 50 to $100 \mathrm{ml}$, but measuring the actual volume the mean error was $56.3 \% .^{12}$ Roehrborn et al ${ }^{13}$ suggest to estimate the post micturition residual with

$$
V=\frac{4}{3} \pi \cdot d \cdot h \cdot w \mathrm{ml}^{3}
$$

but do not mention their mean error. In transrectal ultrasound, the formula $V \approx(5.3 \cdot d \cdot h-21) \mathrm{ml}^{3}$ tested by Haylen et $a l^{14}$ on bladder volumes up to $175 \mathrm{ml}$ in male patients produced a mean error of $16 \%$. If transvaginal ultrasound was carried out, the mean error was $23 \%$ over a range up to $175 \mathrm{ml}$ and the calculation was done with $V \approx(5.9 \cdot d \cdot h-14.6) \mathrm{ml}^{3} .{ }^{15}$ To calculate the post micturition residual volume we used the formula $V=0.7 \cdot d \cdot h \cdot w \mathrm{ml}^{3}$, overestimating the residuals according to Akino et $a l^{12}$ but underestimating it according to Bis et al. ${ }^{10}$ 